\title{
Epilogue: \\ Rethinking digital literacy: \\ Media education in the age of digital capitalism
}

\author{
David Buckingham \\ ddbuckingham1@gmail.com \\ Loughborough University, UK \\ King's College London, UK
}

\begin{abstract}
Advocates of digital education have increasingly recognized the need for young people to acquire digital media literacy. However, this idea is often seen in instrumental terms, and is rarely implemented in any coherent or comprehensive way. This paper suggests that we need to move beyond a binary view of digital media as offering risks and opportunities for young people, and the narrow ideas of digital skills and internet safety to which it gives rise. The article propose that we should take a broader and more critical approach to the rise of 'digital capitalism', and to the ubiquity of digital media in everyday life. In this sense, the paper argue that the well-established conceptual framework and pedagogical strategies of media education can and should be extended to meet the new challenges posed by digital and social media.

This article presents some reflections as an epigraph of the special issue "Digital learning: distraction or default for the future", whose final result has allowed us to group a set of critical research and analysis on the inclusion of digital technologies in educational contexts. The points of view presented in this epigraph is also developed in more detail in the book "The Media Education Manifesto" (Buckingham, 2019).
\end{abstract}

\section{Keywords}

Digital literacy; media education; digital education; digital capitalism 


\section{Introduction. Back to the future Introduction}

When it comes to digital education, policy-makers are often infatuated by fantasies about the future. Yet these fantasies have a history - and at times of change, it is important to look back as well as forward. It's now sixty years since the first message was sent over the ARPANET, the precursor of today's internet; and thirty years since the origin of the World Wide Web. As we know, much of this technology was initially developed for military purposes; but it quickly became surrounded by some very different ideas about how it might be used.

When new technologies emerge, they are often greeted with a combination of hope and fear. In the early years of the internet, utopian views tended to prevail. These ideas emerged from the hippy counter-culture of the late 1960s: networked digital technology was proclaimed as a revolutionary force, a way of giving power to the people. Technology, we were told, would give us access to an infinite world of knowledge; it would promote new forms of creativity; it would encourage smallscale, artisanal businesses; and it would revive democracy. Over time, these early countercultural ideas about social revolution gradually merged with a new kind of entrepreneurial capitalist thinking. After the dot-com crash, the internet was rebranded as a 'participatory' medium (Web 2.0), and these utopian ideas became part of the new business model that I will be calling 'digital capitalism'.

Of course, this utopian view is based on a highly deterministic account of technology. It's as though technology arrives from nowhere, by some magical process, and transforms society and individuals, almost irrespective of how it is used or who is using it. We can see some of the same ideas in education as well. Technology companies like Apple have been particularly skillful in targeting the education market with a similar kind of 'cyber-utopianism'. Technology, we are told, will transform learning, empower students, and liberate teachers. It will automatically bring about more active, creative, student-centred forms of education: anybody who opposes it is simply a dinosaur.

Even the most optimistic advocates would have to acknowledge that the reality has been very different from the rhetoric. The democratic dream of the networked society has a very bitter taste today: far from promoting deliberation and informed debate, social media are arguably contributing to their demise; and the digital world is increasingly dominated by a small number of commercial companies that are unaccountable to nobody but their shareholders. When it comes to education, we have seen a similar history of failed promises about the transformative effects of technology. In fact, it's possible to trace similar arguments being made about the advent of television, or video, or film, many decades earlier. According to their advocates (and their marketers) each of these technologies was also going to liberate teachers and students. Yet in practice, these new devices were rarely used in such a way.

In my view, this is true with digital technology as well. We know that this technology can be part of broader educational change: where we have inspiring teachers, they can also use technology in inspiring ways. But when we look at how digital technology is mostly taken up in education, we find that it is often used in quite narrow and reductive ways - for testing rather than teaching, for gathering data, for improving management efficiency. Very rarely is it used to support more creative, student-centred learning.

Furthermore, the use of technology in school often fails to connect with what children are doing with technology outside school. These days, most young people are walking around with powerful computers ('smartphones') in their pockets: they use them to access information, but also for communication and for entertainment. Yet in many cases, these devices are actually banned in schools. Students aren't invited to study and critically reflect upon the wider digital culture in which they live: they can only use computers for instrumental purposes. 


\section{The coming of the tech-last}

In the past couple of years, the debate on these issues has changed quite significantly. The dream of technological liberation is giving way to a nightmare. Even many of the executives of the technology companies are beginning to lose some of their optimism: some of them publicly admit that they won't allow their own children to use these devices. Newspapers and TV news are full of stories about the dangers of social media; almost every month we have new books that are telling us how technology will take us all to hell. Some people are calling this the tech-lash, the technological backlash.

There is a long litany of concerns here. For many years, there has been anxiety about pornography and paedophiles online (and we should not forget that it was pornography that fuelled much of the expansion of the internet in the first place). But now the issues seem much larger: they are about social and personal well-being - about the kind of society we want to live in, the kind of people we want to be, and what we want our children to become. These concerns are very diverse: they are about fake news and disinformation, and the so-called 'post-truth' society; about young people being radicalized and incited to terrorism; about abuse and hate speech and cyberbullying; about surveillance and the invasion of privacy, and the buying and selling of personal data; and about mental health - about narcissism and addiction to social media, about anxiety and depression and self-harm. And the list goes on...

Media scholars know there is a long history of these kinds of concerns. We can look back to debates about the effects of computer games in the 1990s, or video in the 1980s, or television in the $1950 \mathrm{~s}$ and 60s. Many similar claims were being made then - about sex and violence and various other forms of bad behaviour, but also about how these media were destroying children's innocence, and how we were all becoming addicted to media. However, similar arguments were also being made about the cinema in the 1920s, about popular literature and music halls in the late nineteenth century, and even about the dangerous habit of reading novels. In his book The Republic, the ancient Greek philosopher Plato argued that the dramatic poets were particularly harmful for young people because they showed them bad role models. On one level, we might feel that we have seen all of these concerns before: it's just another case of moral panic, or media panic.

There's some truth in this, but we need to take care. Certainly, the evidence for many of these concerns is very limited; and they are often exaggerated by people with other axes to grind. Terms like 'addiction' and 'fake news' tend to oversimplify the issues. However, these are not simply irrational 'panics': they reflect broader changes that are going on in society, and within the economy. We haven't actually seen it all before.

\section{Beyond the binary}

The problem here is that the debate about technology tends to be framed in terms of a binary, especially when it comes to children. As a researcher, I'm frequently asked: are these new technologies good or bad for children? Of course, the answer is: it all depends - on who uses them, for what purpose and in what context. We tend to regard the issues in terms of simple cause-andeffect relationships; and these simplistic questions then lead to some very limited forms of evidence. When it comes to young people, we also suffer from a chronic sentimentality: we see them either as innocent, passive victims or as 'digital natives' who possess some kind of natural wisdom or affinity with technology. 
In reality, the bad and the good - the risks and opportunities of digital media - come together: preventing risks also means restricting opportunities. We seek to give young people 'digital skills', that will enable them to make the most of the opportunities; but we often define those skills in very narrow, instrumental ways. Meanwhile, in seeking to address the problems posed by digital media, policy-makers and commentators continue to look for quick fix solutions - teaching children the basics of internet safety, teaching them the difference between 'fake news' and 'truth', teaching them how it's bad to bully other people. Yet these kinds of bans and warnings are rarely effective. They tend to address the symptoms rather than the deeper causes of what concerns us. What we need - not least in education - is a bigger, more coherent picture.

\section{The bigger picture}

Our media and technological landscape is now dominated by a small number of very large companies. This has been variously called communicative capitalism, platform capitalism or surveillance capitalism - or what I will more simply call digital capitalism. These companies operate, not in the traditional way of media companies, by selling content (although they are doing that as well), but by gathering and selling data. This is the famous line: if the service is free, then you are the product - or at least your data is the product that is being bought and sold. This was made dramatically clear by the scandal of Cambridge Analytica - the company that harvested data from eighty million Facebook users and sold it to Donald Trump's presidential campaign. This is by no means an isolated example, but a symptom of how this new business model operates.

Several of these companies are more or less monopolies. Facebook, for example, claims to have 2.2 billion active users, about $30 \%$ of the world's population. No other social network comes close; and Facebook has also bought up most of its potential rivals, like Instagram and WhatsApp. Meanwhile, more than $90 \%$ of internet searches, about 3.5 billion searches every day, are on Google. Here too, the competitors are utterly trivial by comparison. Google is in fact the world's largest media company: it is twice as big as the second company, Disney. Google's parent company Alphabet also owns YouTube, which is very much the market leader in multimedia sites, with around $80 \%$ of the market share, or around 5 billion videos watched every day (along with the advertising).

For its part, Amazon dominates online retail: in the US, it now accounts for half of the market - a market that is growing all the time, as old-style bricks-and-mortar shops are disappearing. Jeff Bezos, who owns Amazon, is officially the world's richest man. Meanwhile, Apple began as a hardware company, with a group of massively successful devices: over one billion iPhones have been sold. But, like Amazon, it is increasingly moving into media production and distribution. Both companies create and distribute their own media content, including music and movies. They are competing in this with Netflix, which is now a serious threat to traditional TV broadcasting: at the time of writing (2019), the company has a market capitalization of $\$ 144$ billion, and its revenue is rising by $40 \%$ a year, which would be phenomenal in any industry. These companies - the FAANGs, as they are sometimes called - have different profiles and histories, but they are among the most profitable companies of any kind in the world, and they are working hard to keep it that way.

The companies I've mentioned work by maximizing traffic, using algorithms that for most of us are completely invisible. The aim is to keep us clicking, because clicks mean data, and data means income. In a world of mobile devices, 'virtual assistants' and the 'internet of things', media have become ubiquitous: as in the film The Matrix, it is becoming harder and harder to tell where the media begin and end. This is something that's often seen to apply mainly to younger people or to 'millennials': much of the debate is framed in rather stereotypical generational terms. To be sure, 
there are different patterns of adoption of technology among older and younger people. Some younger people pick up on some devices and services before older people; but in some cases, older people use them first. This increasing ubiquity of media applies to all of us. We're moving quite quickly to a situation where our whole society - our political system, our economy, our arts and culture, our working lives, as well as our social and intimate relationships - are suffused with media technology. Almost everything is mediated.

\section{The limits of (digital) media literacy}

In the past couple of decades, many people have begun to look to 'media literacy' as a potential response to this situation. It's important at this point to distinguish between media literacy, as it's commonly defined, and media education. In the UK, media education - that is, teaching about media in schools - has a long history, going back at least eighty years. Teachers of English (language and literature) have been teaching about media in quite systematic ways since the 1960s; and the earliest specialized courses in Media Studies for high-school students date back to the 1970s. By contrast, the term 'media literacy' only began to be widely used in UK at the beginning of the millennium: it would seem to be a fairly neutral term, but it has distinct political functions.

Media literacy is frequently regarded as a substitute for centralized regulation. Broadly speaking, governments have become increasingly wary of regulating the market in media and technology. This is partly for political reasons, but it's also because they recognise the genuine obstacles to doing so. It's very difficult for national governments to regulate global media companies; and this is even harder with a decentralized technology like the internet, where users are generating much of the content themselves. Of course, the companies themselves don't want regulation, because that would threaten their basic business model, and their enormous profitability. If governments and companies are unwilling to regulate, media literacy provides an apparently democratic alternative: markets cannot be regulated, so consumers need to regulate themselves.

In this context, there has been a good deal of lip-service paid to the idea of media literacy, both by policy-makers and by media companies. But much of the responsibility for actually implementing media literacy falls to educators. Teachers will be very familiar with this kind of 'solutionism'. We have a social problem - drugs, teenage pregnancy, fake news - and the answer is always more education. The buck is passed to educators. And educators are in a paradoxical position here. Media educators have been teaching about many of these issues for many years - although we have often been marginalized and derided. We know how to teach about issues like 'fake news', although we would be inclined to see them as broader and more complex phenomena. Many of us have spent many years arguing and pushing for media education, and now we imagine our time has come. However, we should be careful what we wish for.

The story of media literacy in the UK is not a happy one. In 2003, we had a new Communications Act, which combined the regulation of old media - not the press, significantly, but broadcasting with telecommunications regulation. It created a new regulatory body called Ofcom, the Office of Communication. Among other things, Ofcom was given the responsibility to both define and promote 'media literacy'. It appeared to some that the government was creating a new 'superregulator', but in fact it was generally backing away from regulating the market. As in many other areas of social policy, responsibility for regulation was being passed from the government to the individual consumer. People were expected to regulate their own uses of media, and to cope with the problems of the emerging media and communications environment. And in order to do so, they would have to become competent - or 'media literate'. 
While media literacy became a fashionable slogan in communications policy, it was never a priority for education policy. Essentially, we had a lot of talk about media literacy, but no means of actually implementing it through a systematic programme of education. For the embattled minority of media educators, media literacy was about critical understanding of media; but in the world of communications policy, it gradually became narrower and narrower in scope. Media literacy was reduced to a matter of internet safety and basic digital skills, especially for disadvantaged people.

Media literacy faded from the policy agenda somewhat after the change of government in 2010, although in the last couple of years it has begun to reappear. Now media literacy is even more explicitly seen as a means of dealing with 'media problems'. A new problem comes over the horizon - fake news, cyberbullying, online radicalization, smartphone addiction - and the search is on for the quick fix. We have a problem with internet safety: let's give children lessons to warn them about all the paedophiles on the internet. We have a problem with fake news: so let's teach children to tell the difference between lies and truth. Unfortunately, these issues are much more complex and difficult to teach about than policy-makers imagine. But there is a larger problem here: looking at symptoms rather than causes, and looking at problems in isolation from each other, inevitably results in very fragmentary solutions. Many of these solutions are defensive or protectionist: media literacy seems to be about constantly warning children about all these bad things that they need to avoid, often in highly alarmist and melodramatic ways. And educators mostly understand that warnings of this kind are not a very effective teaching strategy.

\section{The case for media education}

Media literacy requires media education. If it is to be anything more than an empty gesture, media literacy needs sustained programmes of teaching and learning. What that means in schools is that we need to teach about media and technology. Many teachers teach with technology, or through technology: they use computers just as they used to use educational television. However, we also need to be teaching about these media - asking critical questions about how they represent the world, and how they create meanings. We also need to engage much more directly and systematically with how students are using media and technology outside the classroom.

Policy-makers will often agree that students need 'digital literacy'. But digital literacy is mostly defined in very functional and instrumental terms: it is about the ability to manipulate hardware or software. Media education is much more ambitious and more comprehensive that this. While it does promote creative uses of media, it is centrally concerned with critical thinking. It is significantly more challenging than simply warning children about bad things.

'Critical thinking' can be a vague term as well, so we need to define it. Since the 1970 s, media educators in the UK have been using a set of four critical concepts, for looking at film, television, newspapers, computer games, and so on. I believe we can use these concepts very easily to teach about digital and social media as well.

The first concept is media language. What we're looking at here is how media create meaning, or how we create meanings from media; and in this context, 'language' obviously includes forms of visual and audio-visual language. Studying media language takes us beyond the view of the internet as a free space where people simply 'express themselves'. Social media like Facebook and Twitter are not open forums: they have rules and conventions that determine the kinds of language that are possible, and how people behave.

Secondly, representation. Here we're looking at how media claim to represent reality. This takes us beyond the view of digital media as mere 'information' technologies. It's often assumed that information is a neutral good; that it comes down the wire, into the screen and into our brains. The 
only thing we need to learn is how to find it. But from a media education respective, we need to ask questions about how reliable and credible this information is, and how far we should we trust what it is telling us about the world.

In exploring the concept of production, we're asking who makes these media, how they make them and why; and how media are distributed and regulated. This applies whether media are made by large corporations, or by individuals. As I've suggested, the key insight here is that these media are not free, even if they appear to be. Data-based business models work in different ways from those of traditional media such as television, but they are still controlled by very large companies.

Finally, in looking at audiences, we're looking at who uses these media, how they use them and why. The key point here is that digital and social media are not just about empowerment or selfexpression. They may be about creativity, but they are also about surveillance - about companies gathering data about what all of us are doing, click by click. In studying this area, we need to reflect on how and why we use these media in our daily lives, and the broader social, ethical and psychological consequences of this.

\section{The case of 'fake news'}

In order to illustrate this approach in a little more detail, I'd like to take the example of so-called fake news. Over the past couple of years, we've become familiar with the claims that there is an epidemic of fake news, that it's undermining democracy, and that it's a manifestation of a kind of global information war. Yet 'fake news' has become an easy accusation - not least on the part of people like Donald Trump, who might well be regarded as one of its leading purveyors. We need to take care with the term itself, and with the evidence about it. What counts as fake news? How widely is it being spread, how prevalent is it, and how do we assess its influence? There is a distinct danger here of exaggeration, even of media panic.

'Fake news' should be seen as a symptom of much bigger economic and political changes. On one level, fake news is a form of clickbait. It is something that encourages people to click, to distribute, to like or indeed to hate: this is how it generates money for media businesses. In the case of the Trump campaign in 2016, it emerged that a good deal of the so-called fake news was coming from a small town in Macedonia, in the Balkans: a group of teenagers had discovered they could make a lot of advertising revenue from putting up fake news. They didn't care about the politics: they just found that telling Donald Trump supporters what they imagined they wanted was a very good way of making money.

Fake news is obviously a symptom of political changes as well. We're dealing with a more polarized political climate, where conspiracy theories of many kinds are becoming much more popular and widespread. However, these changes are not caused by fake news: it is a symptom and not the primary cause. If we place all the blame on fake news, we run the risk of oversimplifying or distracting attention from the bigger issues at stake. There's also a danger in thinking that if we fix the problem of fake news, then we've solved all these other problems as well.

Some argue that there can be technological solutions to fake news. The technology companies tell us that they will create an algorithm that will eradicate it; and it's possible to buy computer games or apps that will apparently detect it. Facebook periodically promises to employ fact-checkers who will tell us the difference between facts and lies. Other solutions place the responsibility on the user; and there are numerous fake news checklists and toolkits available. There are often some good suggestions here: for example, you should look at the visual design of a website, which may well be part of how it claims to be a reliable authority; you should consider the sources of stories and cross-check between different sources; and so on. This is all useful, although I doubt that most people will use these kinds of checklists consistently. 
As ever, 'media literacy' is often presented as another potential solution here. Yet there's a danger in assuming that this is something that you can teach in a very simple way. In particular, there is a problem in assuming that we can very easily distinguish between truth and falsehood. Of course, there are truths and there are lies, but the difficulty is the grey area in the middle. Most of what we come across has elements of both: it contains half-truths or quarter-truths that can serve to make it credible. What we need here is more than a checklist: we need critical thinking. The other danger here is the assumption that once we've identified the fake news, then the 'real' news is absolutely fine. But critical thinking has to apply to the work of professional journalists and news organisations just as much as to fake news.

We need more than a 'quick fix' here. In media education, we have a long history of teaching about news - about bias, objectivity, fairness, balance, and so forth. We know that these are complicated issues, which are not simply about truth and lies. In teaching, we look at how the news sets an agenda, how it frames a given topic, how language defines and constructs issues, and how journalists and readers interpret a story. We are also aware that news isn't just about rational processes of understanding: there are emotional and symbolic dimensions as well, and engaging with news is not something we can make into a completely rational process through education. Checklists are not enough to help us really understand the complexity of this process: a simple 'quick fix' solution is not going to do the job.

One way forward is to take the four concepts that we are very familiar with through looking at 'old' news - newspapers, television - and apply them to digital news. We can look at the language of news, including both the verbal and visual dimensions, as well as the role of hyperlinks and aspects of digital 'language'. We can look at representation: how news is selected, how stories are put together, how we are given particular interpretations of events. We can look at production, at the sources and producers of digital news, and how they are (or are not) regulated. And we can look at audiences, at how people use and circulate such material, how and why they participate, and how far they trust what they read.

This approach involves both critical analysis and creative production. A few years ago, I worked with some colleagues to produce a teaching pack for primary schools called Developing Media Literacy. We used a very familiar approach of getting the children to create their own news. We gave them raw material and they had to edit and write and then videotape their own news productions. In the process, they had to think about the language they were going to use, including the visual language. What was their studio going to look like? What would their presenter be wearing? They had to think about which stories they would select, how they would sequence them, which images they would use, and how they would create narratives. They acted in role as different kinds of media companies, and we got some children in the class to be regulators who would 'fine' the other children if they didn't tell the truth. And we also asked them to think about different audiences: for example, if you made a news programme for children rather than adults, what difference would that make?

Our experience shows that it's possible for quite young children to engage with these difficult conceptual issues in a very creative, practical way. It's also easy to see how this approach could be extended to the production of news using digital platforms - and indeed to the creation and distribution of information much more broadly.

\section{We need education - but we also need regulation!}

I've argued that media literacy should be more than a well-meaning slogan: it requires media education as a systematic program of teaching and learning for all children. However, that doesn't 
mean we don't need regulation as well: we need both. Media education isn't just about the individual learning to cope: it's also about demanding change. There are many ways in which governments regulate markets for the public good; and in the same way, we need to think hard about how we make these digital media companies operate for the public good. There are several issues at stake here.

One of the responses of the internet companies to the fake news problem has been to suggest that they are not responsible for content. But Facebook and others are not just technology companies, they are media companies: they publish and distribute media content, irrespective of who creates it. And there needs to be some way to regulate that content. A clear example would be political advertising. When it comes to television, we do not allow indiscriminate political advertising. In most democracies, television channels are required to represent a balance of political views. However, on the internet that doesn't apply. We need to find ways of extending such forms of content regulation from 'old media' to new media.

Another issue is privacy. As I've suggested, we now have a media system that is based on collecting people's data without them necessarily knowing what is happening. When we tick a box to accept the terms and conditions of a particular platform, few of us actually read them. Yet often we are signing away the rights to our data. We need at least greater transparency about this. It may be that we accept the contract nevertheless, but we need to be better informed about how the whole process works, and how it can be abused.

Access should be another major focus. The emerging issue here is that of net neutrality: the ability of companies to purchase better internet access to promote their goods. This raises fundamental questions about who really owns and controls the infrastructure. Within capitalism, governments often recognize that monopoly is not necessarily the best way to run things. Monopoly does not necessarily always work in the interests of the consumer; and in many areas of business, we actually work to prevent monopolies, and to promote competition. We need to do the same in the field of digital media.

At the very least, these large media and technology companies need to pay their taxes - which at the moment, many do not. Indeed, I would like to see them pay more taxes and I would like to see the money used to promote media educational activities in schools and communities. But that is probably my own kind of utopian thinking...

\section{Conclusion}

Let me sum up. I began by considering some of the failed promises and the growing anxieties about the changing media environment. I argued that much of this anxiety tends to take problems in isolation. It also tends to focus on the symptoms of what is happening rather than the causes. What we lack is a sense of the bigger picture. I've argued that we need more than 'quick fix' solutions to these issues, because they are actually symptoms of bigger changes that are happening in the media landscape, and in the wider social, economic and political sphere. Media education can provide part of this bigger picture. It has a clear critical framework, which is both coherent and comprehensive; and, as I have shown, it can be extended to encompass newly emerging issues. However, media education is not enough on its own. It may be part of the solution to the problem, but we also need media regulation and reform. 


\section{References}

Buckingham, D. (2019). The Media Education Manifesto. New Jersey: Wiley 